University of Wollongong

Research Online

Australian Institute for Innovative Materials -

Papers

Australian Institute for Innovative Materials

$1-1-2019$

Effects of IPA treatment on the photovoltaic performance of bulk heterojunction organic solar cells

\author{
Ali Aghassi \\ University of Wollongong, aa009@uowmail.edu.au \\ Cormac Fay \\ University of Wollongong, cfay@uow.edu.au
}

Follow this and additional works at: https://ro.uow.edu.au/aiimpapers

Part of the Engineering Commons, and the Physical Sciences and Mathematics Commons

Research Online is the open access institutional repository for the University of Wollongong. For further information contact the UOW Library: research-pubs@uow.edu.au 


\title{
Effects of IPA treatment on the photovoltaic performance of bulk heterojunction organic solar cells
}

\author{
Abstract \\ The treatment of the bulk heterojunction $(\mathrm{BHJ})$ active layer by polar solvents such as alcohols is regarded \\ as a simple, yet effective technique to enhance the power conversion efficiency (PCE) of organic solar \\ cells (OSCs). This study investigated the impact of isopropyl alcohol (IPA) on the photovoltaic \\ performance of two BHJ solar cell devices composed of (a) Poly[N-9'-heptadecanyl-2,7-carbazole- \\ alt-5,5-(4',7'-di-2-thienyl-2', 1',3'-benzothiadiazole)] (PCDTBT) and (b) 7,7'-[4,4-Bis(2-ethylhexyl)-4H- \\ silolo[3,2-b:4,5-b'] dithiophene-2,6-diyl]bis [6-fluoro-4-(5'-hexyl-[2,2'- \\ bithiophen]-5-yl)benzo[c][1,2,5]thiadiazole (p-DTS(FBTTh 2 ) 2 as donors and [6,6]-phenyl-C61-butyric acid \\ methyl ester (PC $60 \mathrm{BM}$ ) as the acceptor in both instances. The physical characteristics of the active \\ layers before and after the treatment were established by UV-Vis absorption and water contact angle \\ measurements. The photovoltaic characteristics of the devices were measured using current density- \\ voltage and external quantum efficiency (EQE) measurements. In addition, a light-intensity dependency \\ technique was employed to study the recombination dynamics of charge carriers under steady-state \\ conditions. The finding reveals that the characteristics of the films remain almost unchanged and that \\ none of the key factors contributing to the PCE of the solar cells were significantly influenced by the IPA \\ treatment. It is thus concluded that the treatment with IPA may not be an effective method to enhance the \\ photovoltaic performance of solar cell devices, as opposed to reports within the literature.

\section{Disciplines} \\ Engineering | Physical Sciences and Mathematics

\section{Publication Details} \\ Aghassi, A. \& Fay, C. D. (2019). Effects of IPA treatment on the photovoltaic performance of bulk \\ heterojunction organic solar cells. Journal of Physics and Chemistry of Solids, 130 136-143.
}

This journal article is available at Research Online: https://ro.uow.edu.au/aiimpapers/3494 


\section{photovoltaic performance of bulk}

3

\section{heterojunction organic solar cells}

5 Intelligent Polymer Research Institute, AIIM Faculty, University of Wollongong, Innovation

6 Campus, Squires Way, Wollongong, NSW 2522, Australia.

7 Corresponding Author

8 E-mail: aa009@uowmail.edu.au (Ali Aghassi, Ph.D.)

10 Keywords: Solvent treatment, IPA, polymer solar cells, small molecule, bulk heterojunction,

11 mobility, trap-assisted recombination, water contact angle. 


\section{Abstract}

2 The treatment of the bulk heterojunction (BHJ) active layer by polar solvents such as 3 alcohols is regarded as a simple, yet effective technique to enhance the power conversion 4 efficiency (PCE) of organic solar cells (OSCs). This study investigated the impact of 5 isopropyl alcohol (IPA) on the photovoltaic performance of two BHJ solar cell devices 6 composed of (a) Poly[N-9'-heptadecanyl-2,7-carbazole-alt-5,5-(4',7'-di-2-thienyl-2',1',3'-

7 benzothiadiazole)] (PCDTBT) and (b) 7,7'-[4,4-Bis(2-ethylhexyl)-4H-silolo[3,2-b:4,5-b']

8 dithiophene-2,6-diyl]bis [6-fluoro-4-(5'-hexyl-[2,2'-bithiophen]-5-

9 yl)benzo[c][1,2,5]thiadiazole (p-DTS(FBTTh 2$)_{2}$ as donors and [6,6]-phenyl-C61-butyric acid 10 methyl ester $\left(\mathrm{PC}_{60} \mathrm{BM}\right)$ as the acceptor in both instances. The physical characteristics of the 11 active layers before and after the treatment were established by UV-Vis absorption and water 12 contact angle measurements. The photovoltaic characteristics of the devices were measured 13 using current density-voltage and external quantum efficiency (EQE) measurements. In 14 addition, a light-intensity dependency technique was employed to study the recombination 15 dynamics of charge carriers under steady-state conditions. The finding reveals that the 16 characteristics of the films remain almost unchanged and that none of the key factors 17 contributing to the PCE of the solar cells were significantly influenced by the IPA treatment.

18 It is thus concluded that the treatment with IPA may not be an effective method to enhance 19 the photovoltaic performance of solar cell devices, as opposed to reports within the literature. 


\section{1. Introduction}

2 Solution-processed bulk heterojunction (BHJ) organic solar cells (OSCs) have been

3 studied extensively during the past decade. This is due to their promising potential for

4 developing low-cost, lightweight, and flexible photovoltaic devices [1]. The power

5 conversion efficiency (PCE) of BHJ OSCs have made impressive progress during the last 10

6 years with currently reported efficiencies reaching ca. 14\% [2,3]. However, they are still

7 lagging behind their silicon-based counterpart in terms of their efficiency and operational

8 lifetime - for commercial purposes, further enhancement of the device performance is

9 required. Numerous approaches have been investigated to enhance the PCE of the BHJ OSC

10 including developing new materials [4-6], improving device architecture [7], the introduction

11 of additives [8], post-production solvent treatments [9-19], and interface engineering [20,21].

12 Several studies have shown that the overall performance of OSC can be enhanced as

13 high as $30 \%$ (depending on BHJ system and used alcohol) as a result of solvent treatment

14 using alcohols $[9,19]$. One particular advantage of this approach is that alcohols can be

15 directly applied to the active layer due to the poor solubility of the donor and acceptor

16 materials. The solvent treatment is typically performed by direct exposure of the active layer

17 to a pure alcohol solution for a given time, followed by the removal of the residual by means

18 of spin coating. Methanol is the commonly employed alcohol to treat the BHJ active layers. It

19 is reported that methanol treatment gives rise to enhanced built-in voltage, reduction of series

20 resistance, increased charge carrier mobility and suppressed charge carrier recombination in

21 solar cell devices composed of $\mathrm{PTB} 7: \mathrm{PC}_{70} \mathrm{BM}$ bulk heterojunction [19]. The positive impact

22 of the methanol treatment was mainly attributed to the optimization of nanoscale phase

23 separation [11,12]. This was mainly correlated with the redistribution of the PCBM

24 molecules within the BHJ resulting in dwelling more PCBM molecules near the top surface

25 [13-16]. There are also other reasons reported in the literature including interface 
1 modification between $\mathrm{BHJ}$ and poly(3,4-ethylene dioxythiophene) poly(styrenesulfonate)

2 (PEDOT:PSS) layer [18], and energy barrier reduction between the active layer/metal

3 electrode [9].

4 While the effect of methanol treatment has been extensively investigated, there are only

5 a few reports in the literature considering the impact of other alcohols on the performance of

6 organic solar cells $[9,12,17]$. Isopropyl alcohol (IPA, 2-propanol) is among the solvents

7 whose impact has been investigated within a few BHJ systems. Guo et al. [9] have shown

8 that the photovoltaic parameters of PTB7:PC ${ }_{71} \mathrm{BM}$ BHJ solar cells improved "to a certain

9 extent" following treatment with IPA; a relatively moderate increase of $V_{o c}$ (from 0.62 to 0.66

$10 \mathrm{~V}$ ), $F F$ (from 50 to 52 ) and $J_{s c}$ (from 14.58 to $15.32 \mathrm{~mA} \mathrm{~cm}$ ch $^{-2}$ ) was observed in devices

11 treated with IPA. They have observed no changes in the thickness, crystallinity, optical

12 properties, and surface roughness of the active layer before and after solvent treatment.

13 However, the authors claimed that IPA treatment results in phase separation structures with

14 smaller domains, which led to the improvement of separation, transportation, and collection

15 of charge carriers [9]. Conversely, a lower power conversion efficiency (PCE) was observed

16 when solar cell devices composed of PCDTBT:PC ${ }_{71} \mathrm{BM}$ BHJ was treated with IPA, owing

17 primarily to the reduction of short-circuit current $\left(J_{s c}\right)$. The reduction was further correlated

18 to the extremely uneven surface of the active layer arising from IPA treatment, which gave

19 rise to the trapping of charge carriers [22]. Furthermore, when PTB7:PC ${ }_{71} \mathrm{BM}$ BHJ solar cells

20 were subjected to IPA treatment out using a solvent vapor annealing (SVA) method, the

21 power conversion efficiency of the devices remains almost similar to as-cast devices [23]. It

22 was also reported that surface morphology and charge carrier mobility of devices did not

23 change significantly upon the SVA treatment with IPA. It is therefore evident from the

24 abovementioned contrary results that a thorough study is required to determine whether post-

25 treatment using IPA can be an effective method to enhance PCE of the organic solar cells. 
1 The focus of this study is to systematically examine the impact of the IPA treatment on 2 the key factors determining the PCE of the organic solar cells. To achieve that two bulk 3 heterojunction solar cells consisting of PCDTBT:PC ${ }_{60} \mathrm{BM}$ and p-DTS(FBBTh $)_{2}: \mathrm{PC}_{60} \mathrm{BM}$

4 were subjected to post-production solvent treatment using isopropyl alcohol. The amount of 5 IPA used for the treatment of the active layers was 10, 20, and $35 \mu 1$. The result of the 6 treatment with $35 \mu 1$ are only discussed in the following sections and the current density 7 voltage measurement of all devices treated with IPA are summarized in electronic 8 supplementary information (ESI) (Table S1, Table S2). It was determined that $35 \mu 1$ of IPA 9 not only fully covered the surface area of the substrate but also remained on top of the active 10 layer over the course of the treatment $(1 \mathrm{~min})$. This is similar to the method reported 11 previously [22]. Subsequently, the impact of IPA treatment was probed using a variety of 12 techniques including current density-voltage measurement $(\mathrm{J}-\mathrm{V})$, external quantum efficiency 13 (EQE), UV-Vis absorption, light-intensity dependency and photo-induced charge extraction 14 by linearly increasing voltage (photo-CELIV). In addition, water contact angle (WCA) 15 measurements were used to study the surface composition of the active layer before and after 16 IPA treatment. As a result of this investigation, the impact of the post-treatment on the charge 17 carriers generation, collection, mobility, and recombination is elucidated. 


\section{2. Materials and methods}

\section{2.1. Materials}

7 (anhydrous, purity of > 99.9\%, Sigma-Aldrich), 1,8-diiodooctane (DIO) (Sigma-Aldrich),

8 1,2-dichlorobenzene (o-DCB) (anhydrous, purity of > 99.9\%, Sigma-Aldrich), isopropyl

9 alcohol (IPA) (Sigma-Aldrich) were available commercially and used as received. Poly(3,410 ethylenedioxythiophene)-poly(styrenesulfonate) solution (PEDOT:PSS) (CleviosTM P VP 11 AI4083) was supplied by "Heraeus Deutschland GmbH \& Co." and kept within a dark

PCDTBT (purity of > 99.5\%, Solaris Chem. Inc.), 7,7'-[4,4-Bis(2-ethylhexyl)-4Hsilolo[3,2-b:4,5-b']dithiophene-2,6-diyl]bis[6-fluoro-4-(5'-hexyl-[2,2'-bithiophen]-5yl)benzo[c][1,2,5]thiadiazole $\left(\mathrm{p}-\mathrm{DTS}\left(\mathrm{FBTTh}_{2}\right)_{2}\right)$ (purity of > 99.5\%, 1-Material), and $\mathrm{PC}_{60} \mathrm{BM}$ ((purity of $>99.5 \%$, Solaris Chem. Inc.) (Figure 1a), chlorobenzene (CB) environment and also under ambient temperature and pressure.

\subsection{Device fabrication}

A conventional device structure consisting of ITO/PEDOT:PSS/BHJ active layer/A was used throughout this study (Figure 1b). The ITO-coated glass (Rs $\leq 15 \Omega \mathrm{sq}^{-1}$, Xin Yan Technology LTD) were sonicated sequentially in deionized water, acetone, and IPA, and subsequently treated with UV-Ozone for 20 minutes. The PEDOT:PSS solution was cast at $5000 \mathrm{rpm}$ for $45 \mathrm{~s}$ to form a 30-40 nm thick layer. The PEDOT:PSS coated substrates were then subject to thermal annealing for $10 \mathrm{~min}$ at $120^{\circ} \mathrm{C}$. The active layer solutions composed of PCDTBT:PC ${ }_{60} \mathrm{BM}(1: 4$ donor/acceptor ratio, $20 \mathrm{mg} / \mathrm{ml})$ and p-DTS(FBBTh $\left.{ }_{2}\right)_{2}: \mathrm{PC}_{60} \mathrm{BM}$ (1:1.5 donor/acceptor ratio, $35 \mathrm{mg} / \mathrm{ml})$ were spin-coated on top of the PEDOT:PSS layer to form the active layer with a thickness of $80 \pm 5 \mathrm{~nm}$ and $100 \pm 5 \mathrm{~nm}$, respectively. The thickness of the active layer was measured by a stylus surface profiler (Dektak 150, Veeco). The devices with small molecule active layer were left in the glove box environment for a 
(a)

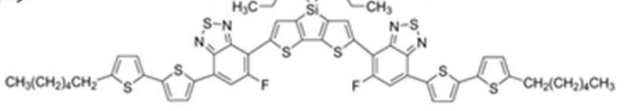

$p$-DTS $\left(\text { FBTTh }_{2}\right)_{2}$

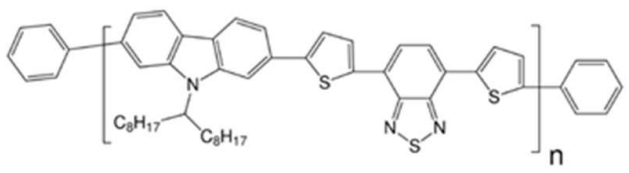

PCDTBT (b)

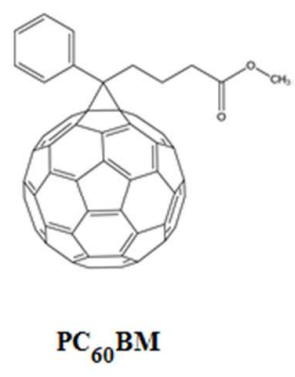

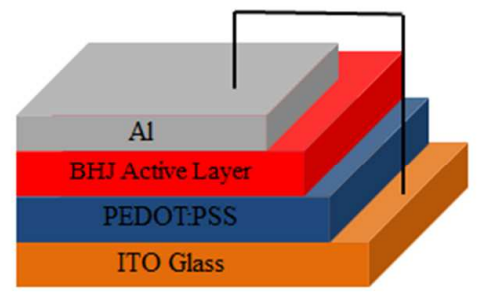

1

2

3

4

5

6

Figure 1. (a) Chemical structures of p-DTS(FBTTh $)_{2}$, PCDTBT and $\mathrm{PC}_{60} \mathrm{BM}$. (b) Schematic of the conventional architecture of organic solar cells used in this study.

further $30 \mathrm{~min}$, followed by annealing at $70{ }^{\circ} \mathrm{C}$ for $10 \mathrm{~min}$ and $80{ }^{\circ} \mathrm{C}$ for $5 \mathrm{~min}$, in order to

remove the residual solvent within the bulk. The IPA treatment of the active layer was carried out before deposition of cathode electrode by dropping $35 \mu \mathrm{l}$ on top of the active layer and removing the residual alcohol after $60 \mathrm{~s}$ (after IPA fully covered substrate surface) via spin casting at $1000 \mathrm{rpm}$ for $60 \mathrm{~s}$. The cathode electrode was finally deposited by thermal evaporation of $100 \mathrm{~nm}$ of aluminum (AVT Services Thermal Evaporator). The active area of the fabricated device was $0.06 \mathrm{~cm}^{2}$.

\subsection{UV-Vis absorption}

A UV-VIS-NIR spectrophotometer (Shimadzu, UV-3600) was used to measure the UV-Vis absorption profile of the BHJ films. The baseline was corrected for through glass absorption using a single point adjustment at $800 \quad \mathrm{~nm}$.

\subsection{Current density-voltage measurement}

A simulated white light illumination of $100 \mathrm{~mW} \mathrm{~cm}^{-2}$ (PV Measurement Inc.) was used to study the device characteristics. The irradiance was calibrated with a standard silicon photovoltaics certified by the National Renewable Energy Laboratory. All encapsulated solar cells were tested in ambient air.

\subsection{Incident photon-to-collected electron (IPCE)}

External quantum efficiency was measured using a QEX10 quantum efficiency measurement system (PV Measurement Inc.). AC mode was chosen for both calibration and 
1 measurement. An increment of $10 \mathrm{~nm}$ was set to record the photocurrent response of the

2 device.

3 2.6. Photo-induced charge extraction with linearly increased voltage (Photo-CELIV):

4 Photo-CELIV measurements were performed using a nanosecond switch (Asama Lab.,

5 SR-05). The role of the switch was to retain the device at open circuit conditions (2.2 M $\Omega$

6 impedance) for a well-defined, adjustable time delay after charge generation [24]. The

7 device was excited by a laser pulse $(532 \mathrm{~nm}, 10 \mathrm{~Hz}$ repetition rate) from a Nd:YAG laser

8 (Spectra-Physics, INDI-40-10), while biased at a voltage similar to the open-circuit potential

9 of the devices in order to compensate for charge extraction under the built-in electric field.

10 The device was kept at open-circuit conditions for an adjustable time delay set by a time

11 delay generator (Stanford Research System, DG535). Then, the photogenerated charge

12 carriers were extracted using a linearly increasing voltage pulse applied by a function

13 generator (NF Corporation, WF1973,). A digital oscilloscope (Tektronix, DPO4054) was

14 employed to record the transient photocurrent (50 $\Omega$ input impedance). 


\section{3. Results and discussion}

\section{3.1. Light and dark current density-voltage measurement}

3 The effect of IPA treatment on the performance of the solar cell devices (a composite of

4 PCDTBT:PC $60 \mathrm{BM}$ blended film) was investigated. Figure $2 \mathrm{a}$ shows current density versus

5 voltage $(J-V)$ characteristics of the devices with and without IPA treatment; under air mass of

61.5 (AM $1.5 \mathrm{G}$ ) and illumination at $100 \mathrm{~W} \mathrm{~cm}^{-2}$. The control device shows open-circuit

7 potential $\left(V_{o c}\right)$ of $910 \pm 7 \mathrm{mV}$, short-circuit current density $\left(J_{s c}\right)$ of $7.8 \pm 0.4 \mathrm{~mA} \mathrm{~cm}{ }^{-2}$, fill

8 factor $(F F)$ of $61.2 \pm 3.2$ resulting in a power conversion efficiency $(P C E)$ of $4.3 \pm 0.2 \%$

9 (average of 10 devices). When the surface of the active layer was treated with $35 \mu$ of IPA,

10 the photovoltaic parameters of the devices - namely, $V_{o c}(904 \pm 12 \mathrm{mV}), J_{s c}(7.7 \pm 0.5 \mathrm{~mA}$

$\left.11 \mathrm{~cm}^{-2}\right)$ and $F F(58 \pm 5.8)$ - decreased slightly, exhibiting a $P C E$ of $4.04 \pm 0.1 \%$ (average of 10

12 devices, Table S1, ESI). The decrease of device performance resulted, primarily, from the fill

13 factor reduction. This implies that the recombination of charge carriers may increase after

14 treatment of the active layer with isopropyl alcohol. These results are in contradiction with

15 the findings reported by Guo et. al, suggesting that IPA treatment enhanced all photovoltaic

16 parameters of solar cells based on PTB7:PC $71 \mathrm{BM} \mathrm{BHJ}$ [9]. Another report shows that IPA

17 improved both $V_{o c}$ and $F F$ of PCDTBT:PC ${ }_{71} \mathrm{BM}$ devices, whereas the $J_{s c}$ was decreased,

18 which resulted in the reduction of device overall efficiency [22].

19 It is reported that the enhancement of $V_{o c}$ following solvent treatment (by methanol)

20 could be due to enhancement of turn-on voltage and subsequently built-in potential $\left(V_{b i}\right)[19]$.

21 The turn-on voltage is an indication of built-in voltage that influences the internal electric

22 field in BHJ solar cells and determines the maximum attainable $V_{o c}$ provided that difference

23 of electrodes' work functions is larger than the offset between HOMO-donor and acceptor-

24 LUMO [19]. To understand the impact of IPA treatment on the turn-on voltage and $V_{b i}$, dark

25 characteristics of the devices before and after the treatment were studied (Figure 2b). It is 
1 clear that there is only quite small difference between dark currents characteristics of the 2 solar cell devices. Both control and IPA treated devices show quite identical turn-on voltage

3 around $0.9 \mathrm{~V}$. This indicates that the built-in voltage $\left(V_{b i}\right)$ of the devices was not enhanced

4 upon treatment. Thus, it can be inferred that unaffected $V_{o c}$ under illumination is associated 5 with unaltered $V_{b i}$. 

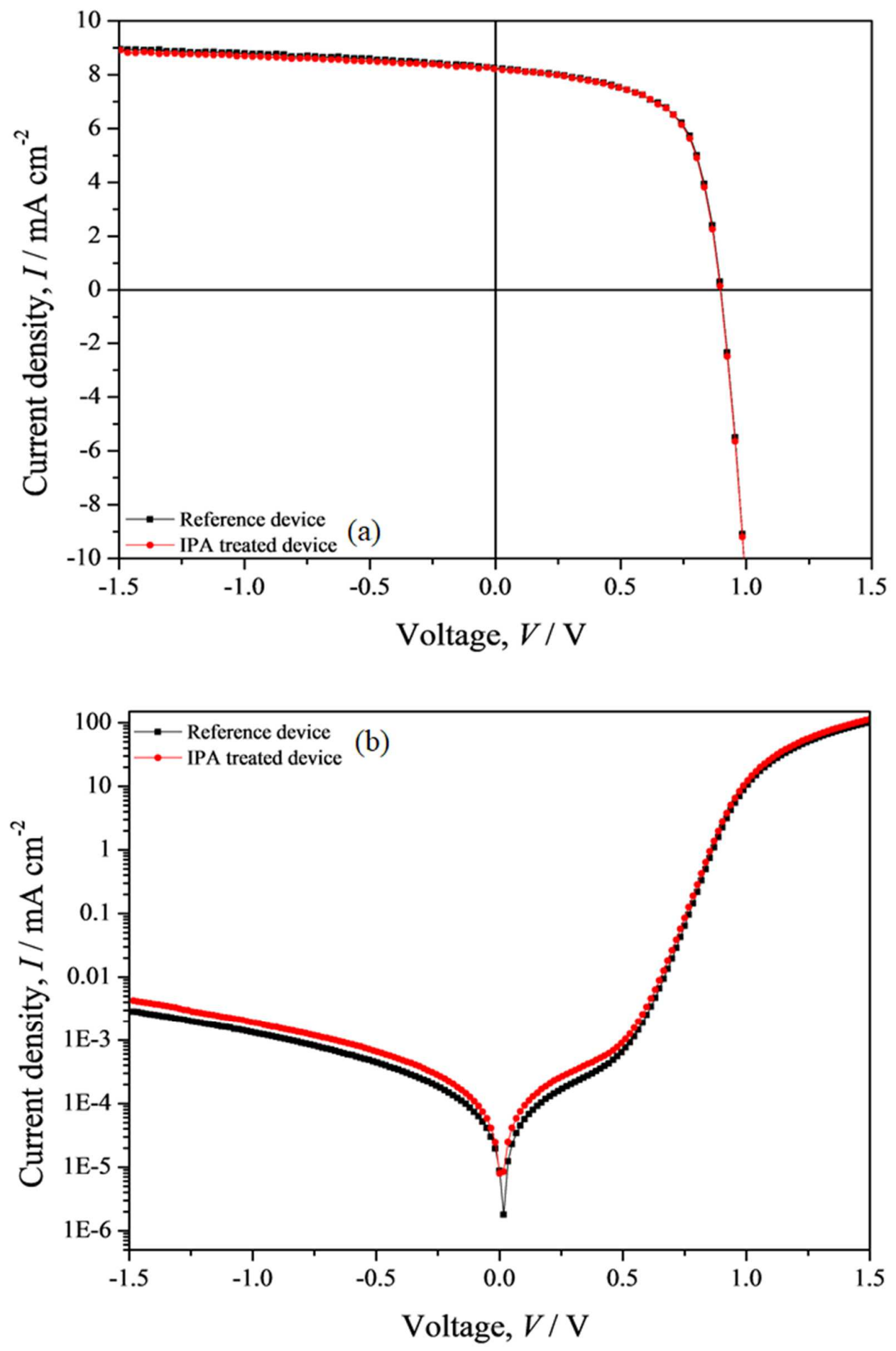

1

2 Figure 2. Comparison of current density-voltage characteristics of the PCDTBT:PC ${ }_{60} \mathrm{BM}$ solar cell devices 3 before and after treatment with IPA (a) top - under illumination of $100 \mathrm{~mW} \mathrm{~cm}^{-2}$, (b) bottom - in the dark. 4 


\section{3.2. EQE and UV-Vis absorption}

2 The EQE spectra of the devices with and without IPA treatment from 300 to $800 \mathrm{~nm}$ is 3 presented in Figure 3a (3 devices, see also Figure S1, ESI). The EQE measurement indicates

4 the percentage of incoming photons that are collected as charge carriers (electrons and holes)

5 at the respective electrodes. The EQE of the control device has two distinct peaks 6 approaching almost ca. 60\%, whereas the EQE of the IPA treated device has similar 7 characteristics with a slightly lower value - specifically in the range from 360 to $600 \mathrm{~nm}$. In 8 addition, the $J_{s c}$ values, obtained by integration of the EQE spectra of the control and IPA 9 treated devices are $8.14 \mathrm{~mA} \mathrm{~cm}^{-2}$ and $8 \mathrm{~mA} \mathrm{~cm}^{-2}$, respectively. These results show that IPA treatment slightly decreases the efficiency of photons to electrons (holes) conversion. The 11 loss in EQE may be a result of a reduction of light absorption, a reduction of charge carrier 12 generation or an increase of charge carrier recombination within the bulk heterojunction [25].

13 To study the effect of IPA on the light absorption of the active layer, Uv-Vis absorption 14 spectroscopy was carried out. Figure $3 \mathrm{~b}$ shows the absorption spectra of the active layer prior 15 to and after treatment with IPA. The absorption of the PCDTBT:PC 60 BM BHJ film subjected 16 to isopropyl alcohol decreases from 350 to $600 \mathrm{~nm}$ and then increases marginally between 17600 to $800 \mathrm{~nm}$ compared to the pristine BHJ film. It can be seen that the absorption peak of 18 PCDTBT between $500-650 \mathrm{~nm}$ did not reduce significantly, nor was it red shifted. This 19 indicates that the crystallinity of PCDTBT remained almost unaffected following IPA 20 treatment. As such, absorption difference of the films can be due to either thickness alteration 21 of the active layer film or internal reconstruction of donor phase [18,19]. The thickness of 22 PCDTBT:PC ${ }_{60} \mathrm{BM}$ BHJ was measured (using a surface profilometer) before and after IPA 23 treatment and no substantial changes in the film thickness $(80 \pm 5 \mathrm{~nm})$ were verified. It is, 24 therefore, speculated that redistribution of $\mathrm{PC}_{60} \mathrm{BM}$ molecules (reconstruction of donor 

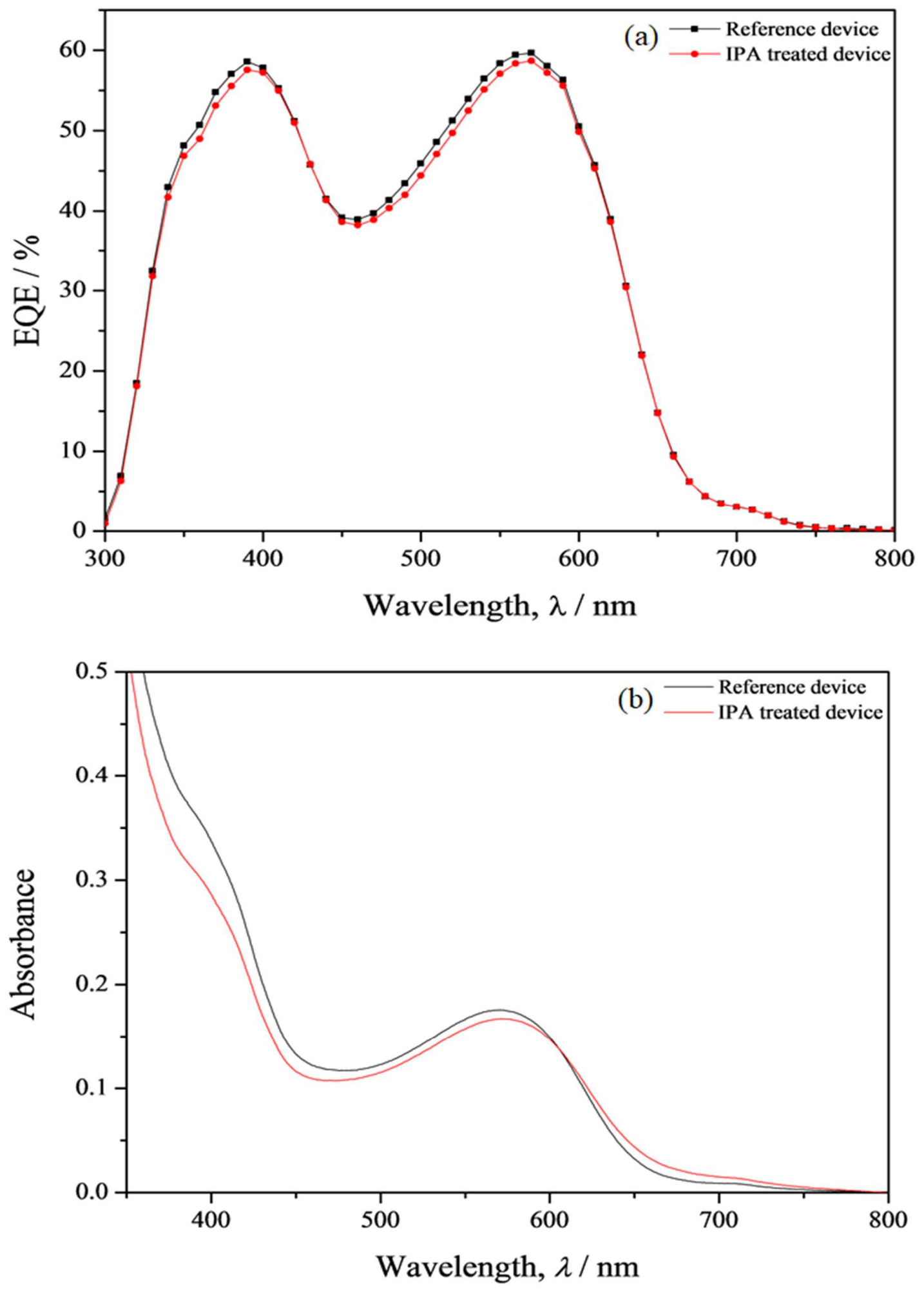

1

2 Figure 3. (a) EQE and (b) UV-Vis spectra of the PCDTBT:PC ${ }_{60} \mathrm{BM}$ blend film before (black line) and after (red 3 line) treatment with $35 \mu 1$ of IPA. 
1 phase) within the active layer may be responsible for the observed reduction. Previous studies

2 have shown that the IPA treatment can result in different impacts on the absorption

3 characteristics, depending on the BHJ systems. For example, absorption of P3HT:PCBM BHJ

4 film was reduced upon treatment with IPA largely due to the aggregation of PCBM

5 molecules [12]. It is suggested that PCBM molecules tend to aggregate to reduce the contact

6 area with the polar solvent [26]. In contrast, the absorption of the BHJ films composed of

$7 \quad$ PCDTBT:PC $70 \mathrm{BM}$ and $\mathrm{PTB} 7: \mathrm{PC}_{70} \mathrm{BM}$ remained almost unchanged after the treatment. This

8 was further correlated with unaltered crystallinity and thickness of the bulk heterojunction

9 films $[9,22]$.

\subsection{Water contact angle measurement}

Several studies have reported that polar solvent treatment (specifically methanol) causes

12 vertical redistribution of the active layer components, leading to increase PCBM content on

13 the top surface (more hydrophilic surface). It was proposed that the fast evaporation of the

14 penetrated methanol in the bulk and its inter-solubility with remnants of active layer solvent

15 (DCB) could drive PCBM molecules to the top surface [12,14]. To examine the influence of

16 the IPA on the vertical redistribution of the active layer component, surface properties of the

17 PCDTBT:PC ${ }_{60} \mathrm{BM}$ blend film was studied using a water contact angle analysis technique.

18 The contact angle of the blended film without treatment was $96 \pm 1.5^{\circ}$ (3 film samples each

19 measured three times, i.e. 9 measurement in total, see Figure 4a and Figure S2, ESI). This

20 indicates that the surface is relatively hydrophobic with a higher concentration of the

21 PCDTBT polymer on the top surface of the blended film. This can be attributed to the higher

22 surface energy of conjugated polymers compared with fullerene derivative. As a result, the

23 polymer tends to accumulate on the top surface of the active layer in order to reduce the

24 overall energy [14,27]. Following exposure of the active layer to isopropyl alcohol, the

25 contact angle of the films remained at the same level (3 film samples each measured 

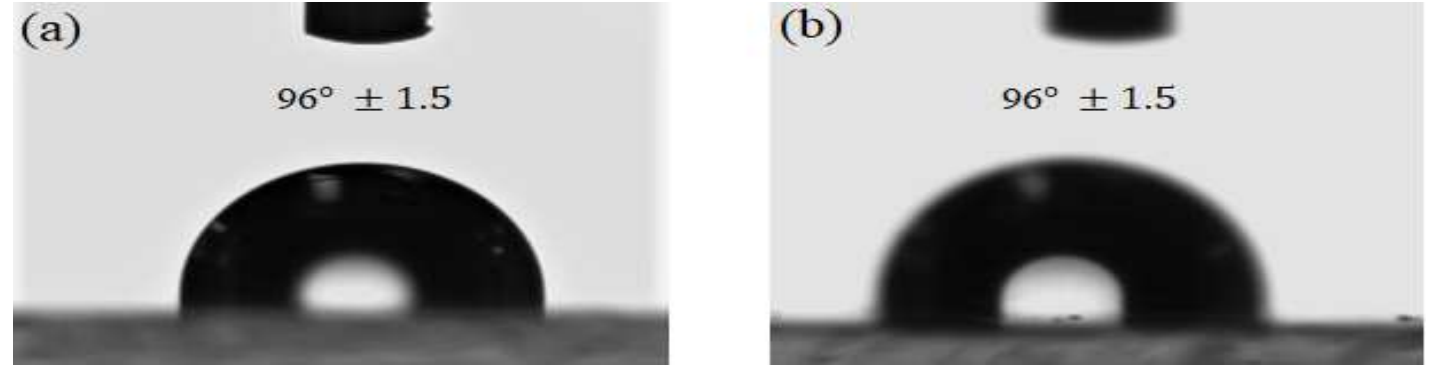

2 Figure 4. Photos of a water droplet on top of PCDTBT:PC60BM blend film treated (a) without and (b) with 35 $3 \mu \mathrm{l}$ of IPA.

4 three times, i.e. 9 measurements in total, see Figure 4b, and Figure S2, ESI), suggesting that

5 the surface content of the bulk heterojunction was not altered. Given the mechanism proposed

6 for methanol, it can be thus surmised that isopropyl alcohol does not substantially drive the

7 PCBM molecules to the top surface of BHJ. This may be due to the relatively high boiling

8 point of the isopropyl alcohol, preventing fast evaporation.

\section{3.4. Charge carrier generation and collection}

To further study the influence of the IPA on the optical properties of the solar cell devices, the photocurrent density $\left(J_{p h}\right)$ was examined with respect to the effective voltage $\left(V_{\text {int }}\right)$. Figure 5a shows the photocurrent density of the devices as a function of effective voltage. The photocurrent density is defined as $J_{p h}=J_{L}-J_{D}$ where $J_{L}$ current density obtained under illumination and $J_{D}$ is dark current. The effective voltage (also called internal voltage) is the voltage difference $\left(V_{i n t}=V_{b i}-V_{a p p}\right)$ between the applied voltage $\left(V_{a p p}\right)$ and the voltage at which the photocurrent density is zero (built-in voltage, $V_{b i}$ ). The effective voltage determines the strength of the electric field within the device and is an indication of driving force for charge extraction. At low effective voltages $(<0.1 \mathrm{~V})$, the photocurrent linearly increases with voltage (Figure 5a). This indicates the competition between the drift and the diffusion of photogenerated charges carriers toward the electrodes [28,29]. The photocurrent density starts to saturate at around $0.2 \mathrm{~V}$ and reaches a plateau (saturated regime) at higher 


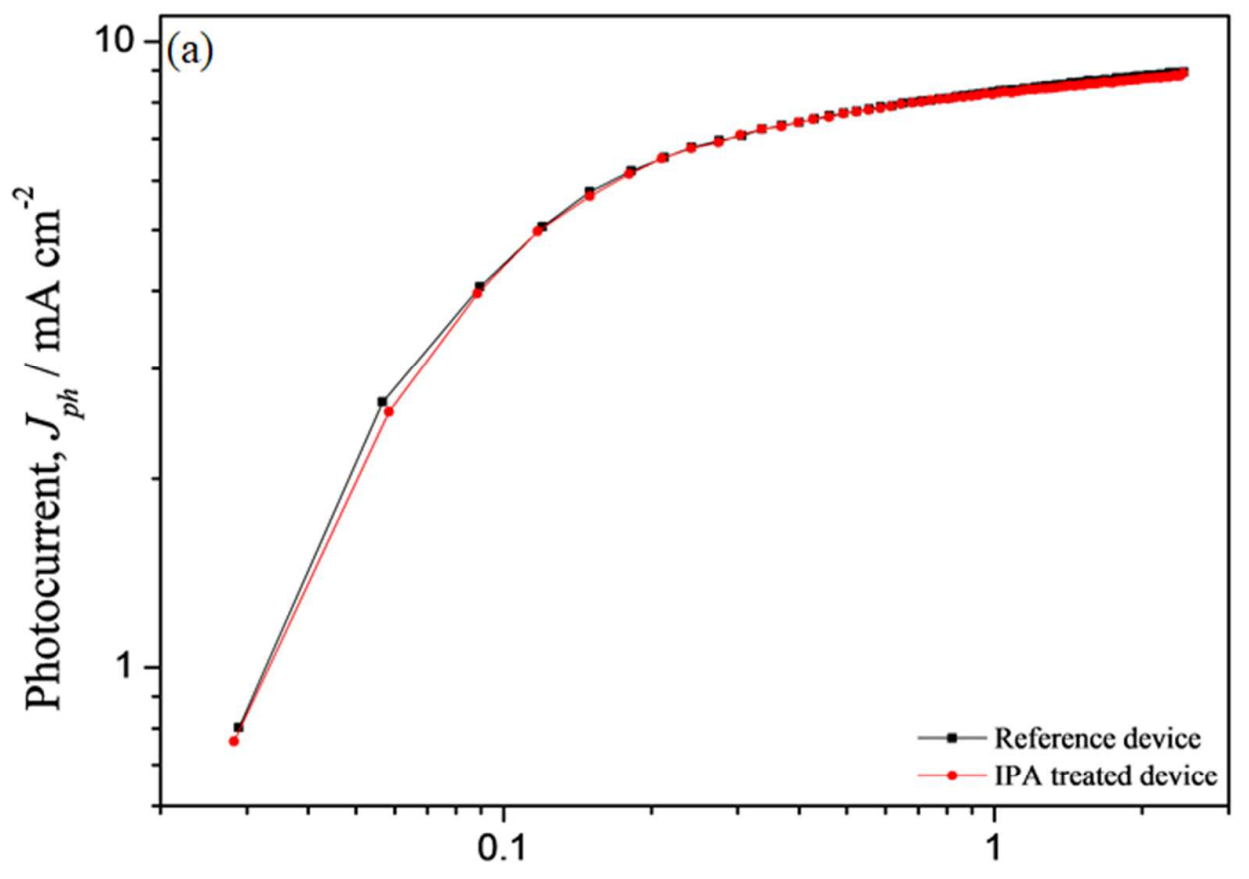

Effective voltage, $V_{\text {int }} / \mathrm{V}$

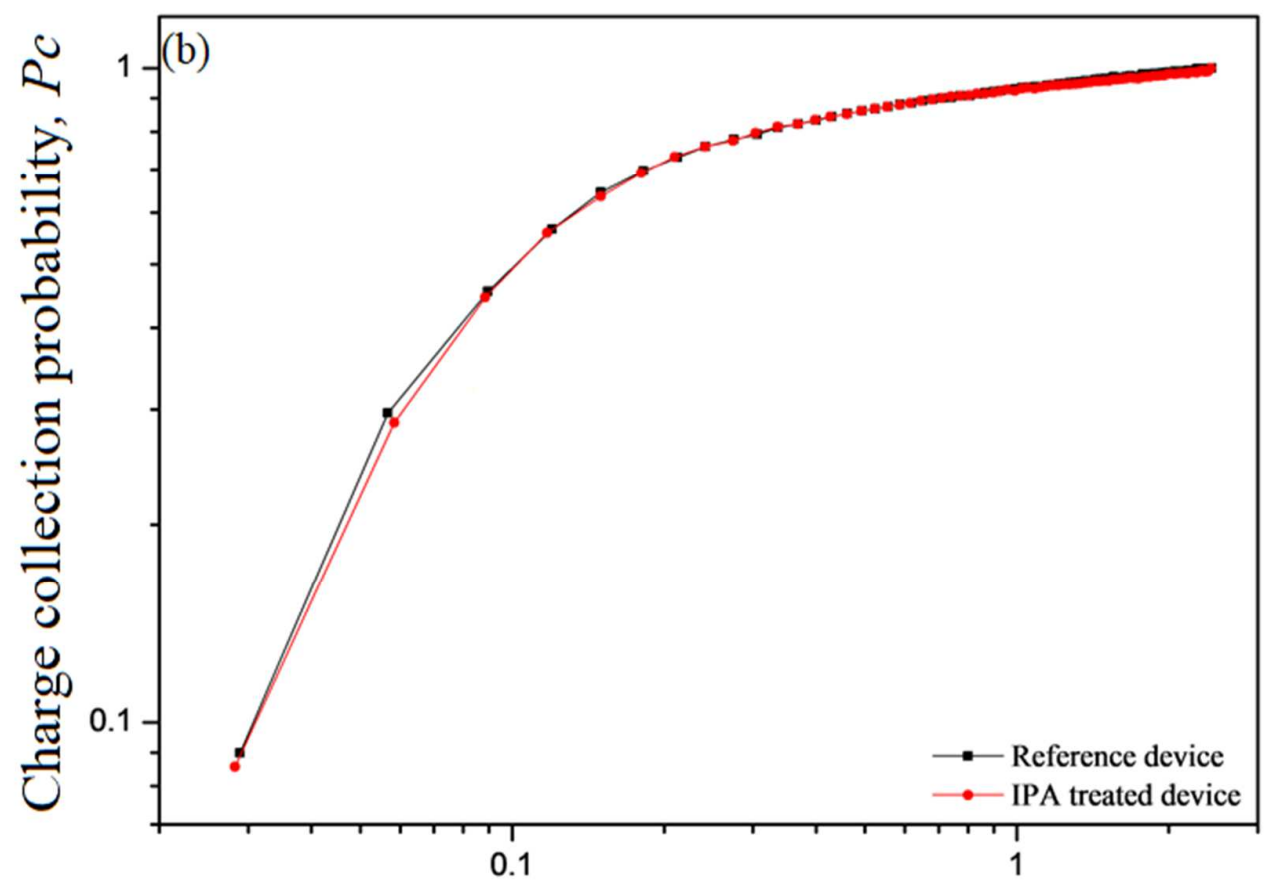

Effective voltage, $V_{\text {int }} / \mathrm{V}$

1

Figure 5. (a) Photocurrent density and (b) charge collection probability as a function of effective voltage $\left(V_{\text {int }}\right)$

3 of the PCDTBT:PC ${ }_{60} \mathrm{BM}$ solar cell devices with (red line) and without (black line) IPA treatment. 
1 effective voltage. This shows that at the saturation regime (high effective voltages and strong

2 electric fields), photo-induced generated excitons are efficiently dissociated into free charge

3 carrier at the interface between donor and acceptor. It can be seen from Figure 4a that

4 treatment with IPA did not change the photocurrent characteristics of the devices across all

5 effective voltages. The saturated photocurrent density is only limited by the number of

6 absorbed incident photons and can be calculated as follows:

$$
\mathrm{J}_{\mathrm{ph}, \mathrm{sat}}=\mathrm{edG}_{\max }
$$

8 where $e$ is elementary charge $\left(1.60217662 \times 10^{-19} \mathrm{C}\right), d$ stands for the thickness of the active 9 layer $(80 \mathrm{~nm})$ and $G_{\max }$ is the maximum photo-induced charge carrier generation rate per unit 10 volume. The calculated values of $G_{\max }$ for the control device and the device treated with $35 \mu 1$ 11 of IPA are $6.971 \times 10^{27} \mathrm{~m}^{-3} \mathrm{~s}^{-1}\left(89.34 \mathrm{~A} \mathrm{~m}^{-2}\right)$ and $6.952 \times 10^{27} \mathrm{~m}^{-3} \mathrm{~s}^{-1}\left(89.1 \mathrm{~A} \mathrm{~m}^{-2}\right)$, 12 respectively (4 devices summarized in Table S3 and 4 devices summarized in Table S4, ESI). 13 The $G_{\max }$ values are almost comparable, which implies that maximum numbers of bound 14 electron-hole pairs that can contribute to the photocurrent have not been affected by the IPA 15 treatment. At saturation, where the photocurrent is independent of temperature and voltage, $16 G_{\max }$ is mainly governed by the number of absorbed photons [30,31]. As such, any changes in $17 G_{\max }$ can be correlated to the alterations in the absorption (optical properties) of the active 18 layer films. Although a slight decrease in absorption was observed (Figure 3b), the overall 19 excitons generation appears to be unaffected upon the solvent treatment. It should also be 20 mentioned that not all of the generated charge carriers can be collected at the respective 21 electrodes. The photocurrent density can be expressed in terms of bias-dependent collection probability $\left(P_{c}\right)$ of charge carriers at the electrodes prior to recombination, as follows:

$$
\mathrm{J}_{\mathrm{ph}}=\mathrm{edG}_{\max } \mathrm{P}_{\mathrm{c}}
$$

24 which, from equation 1 and $2, P_{c}$ can be calculated by normalizing $J_{p h}$ with $J_{p h, s a t .} P_{c}$ 25 approaches unity at sufficiently high effective voltages (reverse bias), which corresponds 
1 with the complete collection of charge carriers at their respective electrodes. Conversely, $P_{c}$

2 decreases at low internal voltages (forward bias) where charge recombination becomes

3 increasingly important [32,33]. As shown in Figure 5b, the $P_{c}$ characteristic of the IPA treated

4 device is virtually identical across a range of effective voltages compared with the control

5 device. Thus, both charge generation and collections characteristics have not been affected by

6 the IPA treatment - two factors which significantly contribute to $J_{s c}$ and fill factor.

\section{$7 \quad$ 3.5. Charge carrier recombination and mobility}

8 In order to gain more of an understanding of recombination dynamics of charge

9 carriers, the variation of $J_{s c}$ was studied as a function of incident light intensity prior to and

10 after treatment with IPA. Previous studies have shown a power law dependence between $J_{s c}$

11 and light intensity (I),

$$
J_{s c} \propto I^{\alpha}
$$

13 where $I$ is the light intensity and $\alpha$ is the exponential factor [32,34-36]. The $\alpha$ exponent 14 demonstrates the strength of the bimolecular recombination under short-circuit conditions.

15 The higher the $\alpha$ value (close to unity), the weaker bimolecular recombination is under short-

16 circuit conditions. In Figure $6 \mathrm{a}, J_{s c}$ of the devices is plotted against light intensity (log-log

17 scale) and subsequently fitted to a power law. Prior to the solvent treatment, the $\alpha$ value was

18 estimated to be 0.81 . Following treatment with IPA, the $\alpha$ value remained unchanged (6

19 devices summarized in Table S5 and 4 devices summarized in Table S6, ESI). This implies

20 that the recombination dynamics of charge carriers at short-circuit conditions are not

21 influenced by the solvent treatment. Furthermore, the values of $\alpha$ (deviation from unity)

22 suggest that charge carriers are likely annihilated via the bimolecular recombination

23 mechanism under short-circuit conditions provided that the space-charge 


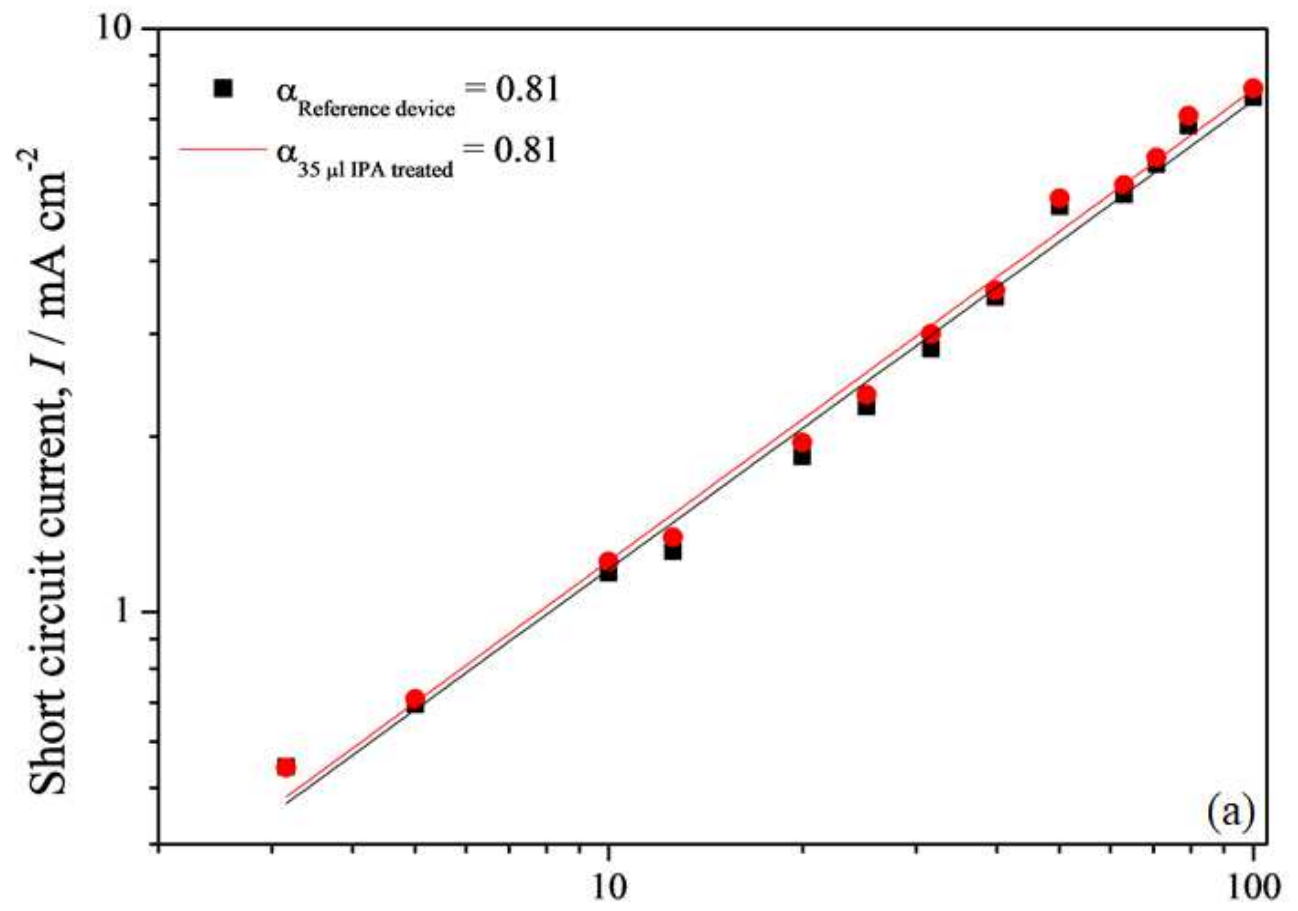

Light intensity $/ \mathrm{mW} \mathrm{cm}^{-2}$

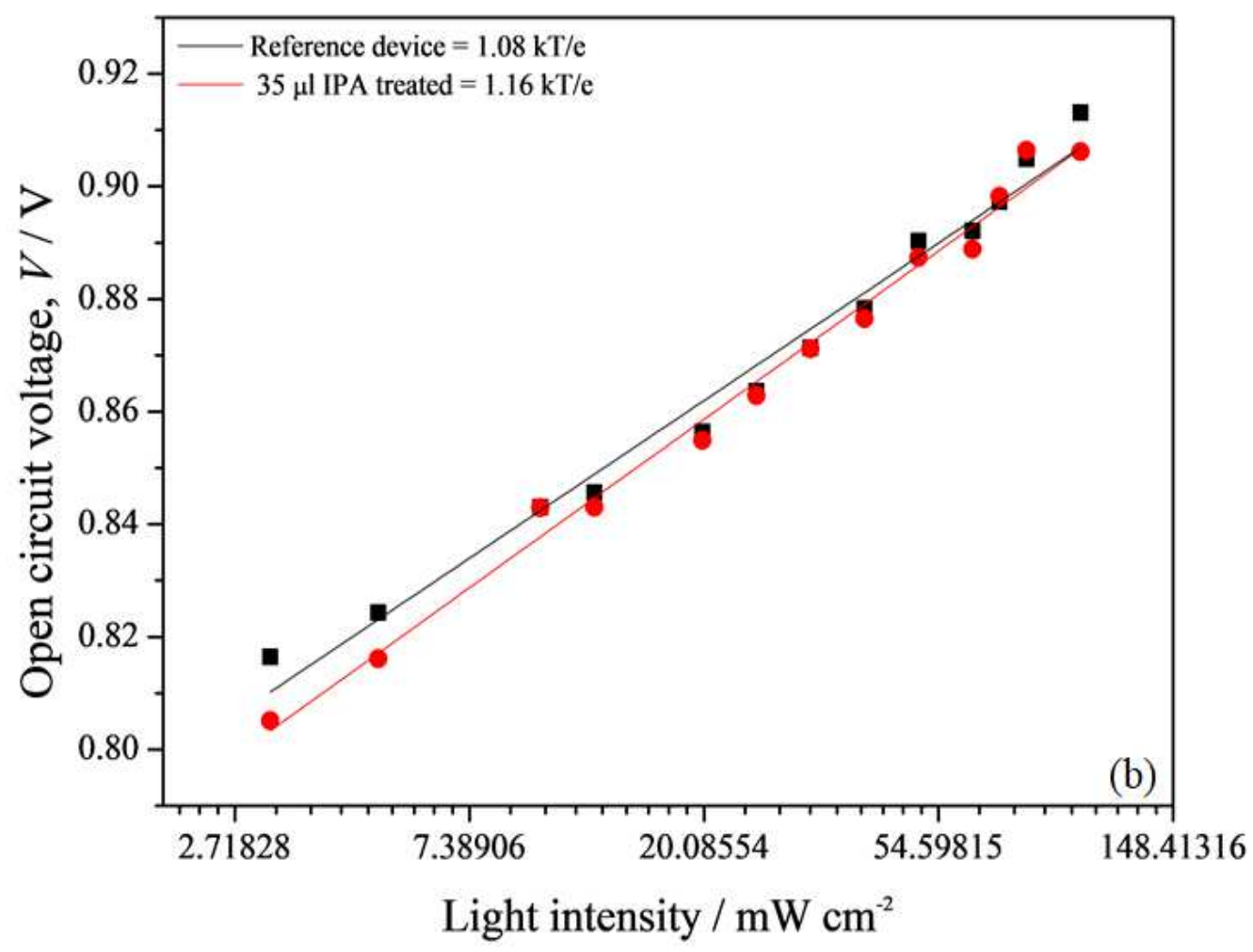

1

2 Figure 6. (a) short-circuit current density and (b) open-circuit potential plotted as a function of the light 3 intensity of the PCDTBT:PC ${ }_{60} \mathrm{BM}$ solar cell devices before and after treatment with IPA. 
1 effect and variation of mobility between electrons and holes are negligible [32,34-36].

2 To examine the space charge and mobility effects on the deviation of $\alpha$ from unity, the 3 charge carrier mobility of the devices was measured using Photo-CELIV technique (Figure

4 S3, ESI). The obtained mobility values for the control device and IPA-treated device were $5 \quad 1.54 \times 10^{-5} \mathrm{~cm}^{2} \mathrm{~V}^{-1} \mathrm{~s}^{-1}$ and $1.49 \times 10^{-5} \mathrm{~cm}^{2} \mathrm{~V}^{-1} \mathrm{~s}^{-1}$, respectively (2 devices summarized in 6 Table S7, ESI). The mobility values are close to the values reported in the literature (ranging 7 from 3 to $\left.5 \times 10^{-5} \mathrm{~cm}^{2} \mathrm{~V}^{-1} \mathrm{~s}^{-1}\right)[22,37,38]$. Therefore, the reduction of $\alpha$ values could not be 8 attributed to space charge effects or mobility discrepancies between holes and electrons 9 across the active layer. Instead, the bimolecular recombination could account for such a 10 reduction. It is worth pointing out that the mobility before and after the treatment is very 11 similar and within experimental error. It is shown that the solvent treatment typically results 12 in a more balanced charge carrier transport within the active layer by largely enhancing the 13 hole mobility $[14,18,19]$. Although the individual charge carrier mobility cannot be 14 determined separately, the mobility obtained from Photo-CELIV technique can be argued to 15 be average mobility of both electrons and holes [39]. As such, any enhancement in either 16 charge carrier due to the solvent treatment could improve the average (overall) mobility of 17 the devices. This is clearly not observed here. Given the unchanged mobility, the reduction of 18 fill factor can be assigned to the increase of charge carrier recombination after direct 19 exposure of the active layer to isopropyl alcohol.

20 Similar to short-circuit conditions, recombination dynamics of the charge carriers can 21 be studied at open-circuit conditions with respect to incident light-intensity variation. At 22 open-circuit conditions, all photogenerated charge carriers recombine, and as a result, there is 23 no net current. For pure bimolecular recombination, the slope of $V_{o c}$ versus natural logarithm 24 of light intensity is equal to $k T / e(0.02586 \mathrm{~V})$, where $k, T$, and $e$ are Boltzmann constant, 25 temperature in Kelvin and elementary charge, respectively. When an additional 
1 recombination process is involved, e.g., Shockley-Read-Hall (SRH) or trap-assisted

2 recombination, a stronger dependence of $V_{o c}$ on light intensity is observed with a slope

3 greater than $k T / e$. Figure $6 \mathrm{~b}$ shows the slopes for the solar cell devices before and after

4 treatment with IPA obtained by plotting $V_{o c}$ versus various light intensities. The control

5 device demonstrates a slope of $1.08 \mathrm{kT} / \mathrm{e}$, whereas a slightly larger slope $(1.16 \mathrm{kT} / \mathrm{e})$ was

6 achieved for the devices subjected to IPA treatment (Tables S5 and S6, ESI). The results

7 suggest that bimolecular recombination is the dominant mechanism at open-circuit

8 conditions. Moreover, a stronger dependence of $V_{o c}$ on light-intensity implies that trap-

9 assisted recombination was slightly intensified upon treatment with IPA. The trap-assisted

10 recombination is significantly dependent on the mobility of the charge carriers [40]. Given

11 that there are no substantial differences between charge carrier mobility before and after the

12 treatment, it is speculated that trapping centers were augmented following the solvent

13 treatment. It is indeed reported that the smooth surface of PCDTBT:PCBM was altered to an

14 extremely uneven surface due to the appearance of anomalous hills following treatment with

15 isopropyl alcohol [22]. Therefore, considering all circumstances the reduction of fill factor

16 and short-circuit current may arise from an increase of trap-assisted recombination following

17 the solvent treatment. While the above results support the scope of this study, it would be

18 advantageous to directly investigate the morphology of the bulk heterojunction before and

19 after IPA treatment by using Grazing-Incidence Wide-Angle X-ray Scattering (GIWAXS)

20 and/or Atomic Force Microscopy (AFM) techniques. This may be lead to deeper

21 understanding of the treatment impact, but it is outside the focus of this paper. 


\section{$1 \quad$ 3.6. Small molecule-based BHJ solar cells}

2 To gain more of an understanding regarding the effect of solvent treatment with IPA, a

3 similar approach was applied to small molecule-based bulk heterojunction solar cells. Figures

$47 \mathrm{a}$ and $7 \mathrm{~b}$ present the $J-V$ characteristics of the p-DTS(FBTTh $)_{2}: \mathrm{PC}_{60} \mathrm{BM} \mathrm{BHJ}$ devices in the

5 dark and under $100 \mathrm{~mW} \mathrm{~cm}^{-2}$ irradiation. The EQE profiles of the devices before and after

6 treatment with IPA are also presented in Figure 7c. The photovoltaic characteristics of the

7 control device and IPA treated devices are summarized in Table 1. Obviously, photovoltaic

8 parameters of the SM BHJ devices following treatment with IPA exhibit imperceptible

9 changes compared to the control devices. The EQE of the devices is almost identical across

10 the spectra. In addition, the absorption of the SM film subjected to IPA treatment was

11 declined specifically between 500 to $700 \mathrm{~nm}$ (Figure S4, ESI). These results indicate that

12 solvent treatment using isopropyl alcohol might not be able to improve the performance of

13 the BHJ solar cells.

14 Table 1. Photovoltaic characteristics of the p-DTS $\left(\mathrm{FBTTh}_{2}\right)_{2}: \mathrm{PC}_{60} \mathrm{BM}$ solar cell devices before (reference) and 15 after treatment with $35 \mu \mathrm{l}$ of IPA. The values are the average of 10 devices (Table S2, ESI).

\begin{tabular}{ccccc}
\hline Device & Voc $_{\text {oc }}(\mathrm{mV})$ & $\mathrm{J}_{\mathrm{sc}}\left(\mathrm{mA} \mathrm{cm}^{-2}\right)$ & FF & PCE (\%) \\
\hline Reference & $730 \pm 7$ & $8 \pm 0.3$ & $55 \pm 2.2$ & $3.2 \pm 0.2$ \\
\hline IPA treated & $733 \pm 5$ & $8 \pm 0.5$ & $56 \pm 1.8$ & $3.3 \pm 0.3$ \\
\hline
\end{tabular}



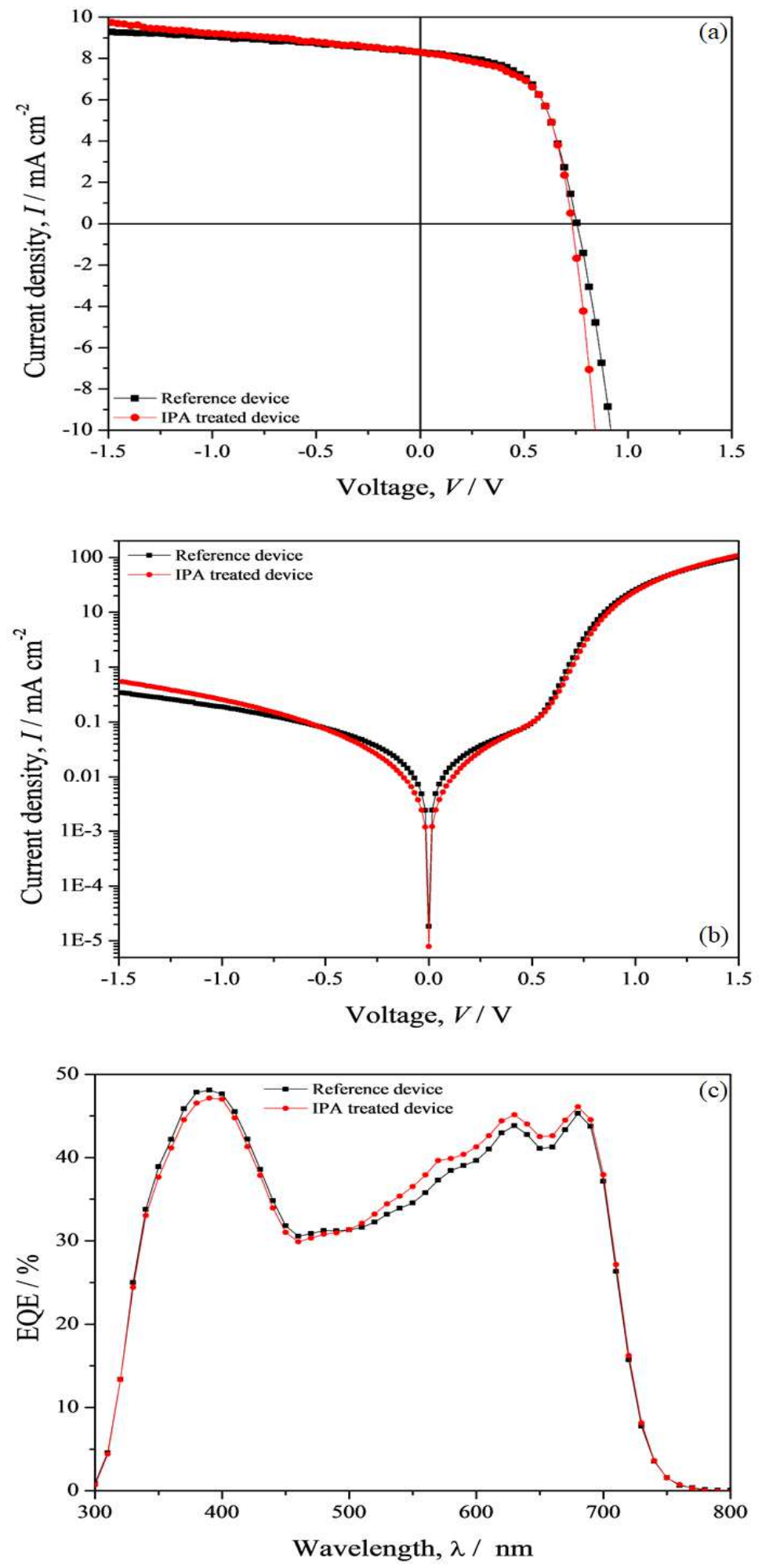

1

2 Figure 7. (a) current density-voltage under $100 \mathrm{~mW} \mathrm{~cm}^{-1}$, (b) dark current characteristics and (c) EQE of the p3 DTS(FBTTh $\left.{ }_{2}\right)_{2}: \mathrm{PC}_{60} \mathrm{BM}$ BHJ solar cell devices before and after treatment with IPA. 


\section{4. Conclusion}

2 A common practice to enhance photovoltaics characteristics of BHJ organic solar cells

3 is to perform facile solvent treatment by using polar solvents such as alcohols. It is suggested

4 that solvent treatment can cause the internal reconstruction of the bulk heterojunction, leading

5 to better charge carrier generation, transportation, and collection and subsequently higher

6 efficiency. In this study, two BHJ systems were subjected to the solvent treatment using

7 isopropyl alcohol. Despite the treatment, no substantial enhancement was observed in the

8 photovoltaic performance of the solar cell devices composed of PCDTBT:PC ${ }_{60} \mathrm{BM}$ and p-

$9 \mathrm{DTS}\left(\mathrm{FBTTh}_{2}\right)_{2}: \mathrm{PC}_{60} \mathrm{BM}$. This is further proven by looking at the critical parameters

10 contributing to the power conversion efficiency such as charge carrier generation, collection,

11 recombination, and mobility whereby all of them remained unchanged or slightly changed.

12 Moreover, WCA measurements indicate that the surface composition of the active layer

13 before and after the treatment is quite similar. It is therefore concluded that not all alcohols

14 can be effective in the post-production solvent treatment for enhancing the BHJ solar cell

15 efficiency. 


\section{Supporting Information}

2 Supplementary data associated with this article can be found, in the online version.

\section{Acknowledgment}

$4 \quad$ This work supported by the Australian Research Council through Discovery Projects

5 funding scheme (project DP110101369) and Australian National Fabrication Facility.

6

7

8 
1

2 [1] N. Yeh, P. Yeh, Organic solar cells: Their developments and potentials, Renewable 3 Sustainable Energy Rev. 21 (2013) 421-431. doi:10.1016/j.rser.2012.12.046.

4 [2] M.A. Green, Y. Hishikawa, E.D. Dunlop, D.H. Levi, J. Hohl-Ebinger, A.W.Y. Ho5 Baillie, Solar cell efficiency tables (version 51), Prog. Photovoltaics Res. Appl. 26 $6 \quad$ (2018) 3-12. doi:10.1002/pip.2978.

7 [3] H. Zhang, H. Yao, J. Hou, J. Zhu, J. Zhang, W. Li, R. Yu, B. Gao, S. Zhang, J. Hou, 8 Over 14\% Efficiency in Organic Solar Cells Enabled by Chlorinated Nonfullerene 9

\section{References} Small-Molecule Acceptors, Adv. Mater. $30 \quad$ (2018) e1800613. doi:10.1002/adma.201800613.

[4] Y.-J. Cheng, S.-H. Yang, C.-S. Hsu, Synthesis of conjugated polymers for organic solar cell applications, Chem. Rev. 109 (2009) 5868-5923. doi:10.1021/cr900182s.

[5] S.D. Collins, N.A. Ran, M.C. Heiber, T.-Q. Nguyen, Small is Powerful: Recent Progress in Solution-Processed Small Molecule Solar Cells, Adv. Energy Mater. 7 (2017) 1602242. doi:10.1002/aenm.201602242.

[6] S.P. Singh, G.D. Sharma, Near infrared organic semiconducting materials for bulk heterojunction and dye-sensitized solar cells, Chem. Rec. 14 (2014) 419-481. doi:10.1002/tcr.201300041.

[7] S. Sista, Z. Hong, L.-M. Chen, Y. Yang, Tandem polymer photovoltaic cells-current status, challenges and future outlook, Energy Environ. Sci. 4 (2011) 1606. doi:10.1039/c0ee00754d.

[8] H.-C. Liao, C.-C. Ho, C.-Y. Chang, M.-H. Jao, S.B. Darling, W.-F. Su, Additives for morphology control in high-efficiency organic solar cells, Mater. Today. 16 (2013) 326336. doi:10.1016/j.mattod.2013.08.013.

[9] S. Guo, B. Cao, W. Wang, J.-F. Moulin, P. Müller-Buschbaum, Effect of alcohol 
1 treatment on the performance of PTB7:PC71BM bulk heterojunction solar cells, ACS

2 Appl. Mater. Interfaces. 7 (2015) 4641-4649. doi:10.1021/am5079418.

3 [10] H. Yu, X. Huang, Y. Li, Z. Wu, Effect of methanol treatment on the performance of 4 P3HT:PC71BM bulk heterojunction solar cells with various cathodes, J. Mater. Sci.:

$5 \quad$ Mater. Electron. 28 (2017) 12909-12915. doi:10.1007/s10854-017-7121-1.

6 [11] H. Li, H. Tang, L. Li, W. Xu, X. Zhao, X. Yang, Solvent-soaking treatment induced 7 morphology evolution in P3HT/PCBM composite films, J. Mater. Chem. 21 (2011) $8 \quad$ 6563. doi:10.1039/cljm10148j.

9 [12] S. Nam, J. Jang, H. Cha, J. Hwang, T.K. An, S. Park, C.E. Park, Effects of direct solvent exposure on the nanoscale morphologies and electrical characteristics of PCBM-based transistors and photovoltaics, J. Mater. Chem. 22 (2012) 5543. doi:10.1039/c2jm15260f.

[13] W. Zhou, H. Chen, J. Lv, Y. Chen, W. Zhang, G. Yu, F. Li, Improving the efficiency of polymer solar cells based on furan-flanked diketopyrrolopyrrole copolymer via solvent additive and methanol treatment, Nanoscale. 7 (2015) 15945-15952. doi:10.1039/c5nr04393j.

[14] B. Guo, W. Zhou, M. Wu, J. Lv, C. Yu, F. Li, Z. Hu, Improving the efficiency of polymer solar cells via a treatment of methanol : water on the active layers, J. Mater. Chem. A Mater. Energy Sustain. 4 (2016) 9644-9652. doi:10.1039/C6TA04026H.

[15] Y. Wang, Y. Liu, S. Chen, R. Peng, Z. Ge, Significant Enhancement of Polymer Solar Cell Performance via Side-Chain Engineering and Simple Solvent Treatment, Chem. Mater. 25 (2013) 3196-3204. doi:10.1021/cm401618h.

[16] L. Ye, Y. Jing, X. Guo, H. Sun, S. Zhang, M. Zhang, L. Huo, J. Hou, Remove the Residual Additives toward Enhanced Efficiency with Higher Reproducibility in Polymer Solar Cells, J. Phys. Chem. C. 117 (2013) 14920-14928. doi:10.1021/jp404395q.

[17] X. Liu, W. Wen, G.C. Bazan, Post-deposition treatment of an arylated-carbazole 
1 conjugated polymer for solar cell fabrication, Adv. Mater. 24 (2012) 4505-4510.

2 doi:10.1002/adma.201201567.

3 [18] K. Zhang, Z. Hu, C. Duan, L. Ying, F. Huang, Y. Cao, The effect of methanol treatment

4 on the performance of polymer solar cells, Nanotechnology. 24 (2013) 484003.

5 doi:10.1088/0957-4484/24/48/484003.

6 [19] H. Zhou, Y. Zhang, J. Seifter, S.D. Collins, C. Luo, G.C. Bazan, T.-Q. Nguyen, A.J.

7 Heeger, High-Efficiency Polymer Solar Cells Enhanced by Solvent Treatment, Adv.

$8 \quad$ Mater. 25 (2013) 1646-1652. doi:10.1002/adma.201204306.

9 [20] R. Steim, F.R. Kogler, C.J. Brabec, Interface materials for organic solar cells, J. Mater.

10 Chem. 20 (2010) 2499. doi:10.1039/b921624c.

11 [21] Z. Yin, J. Wei, Q. Zheng, Interfacial Materials for Organic Solar Cells: Recent 12 Advances and Perspectives, Adv. Sci. 3 (2016) 1500362. doi:10.1002/advs.201500362.

13 [22] X. Zhang, Z. Li, Z. Zhang, S. Li, C. Liu, W. Guo, L. Shen, S. Wen, S. Qu, S. Ruan, 14 Efficiency Improvement of Organic Solar Cells via Introducing Combined Anode Buffer 15 Layer To Facilitate Hole Extraction, J. Phys. Chem. C. 120 (2016) 13954-13962. 16 doi:10.1021/acs.jpcc.6b03697.

17 [23] Effects of different polar solvents for solvent vapor annealing treatment on the 18 performance of polymer solar cells, Org. Electron. 15 (2014) 2647-2653. 19 doi:10.1016/j.orgel.2014.07.026.

20 [24] T.M. Clarke, C. Lungenschmied, J. Peet, N. Drolet, A.J. Mozer, A Comparison of Five 21 Experimental Techniques to Measure Charge Carrier Lifetime in Polymer/Fullerene 22 Solar Cells, Adv. Energy Mater. 5 (2015) 1401345. doi:10.1002/aenm.201401345.

23 [25] S.R. Cowan, W.L. Leong, N. Banerji, G. Dennler, A.J. Heeger, Identifying a Threshold 24 Impurity Level for Organic Solar Cells: Enhanced First-Order Recombination Via Well25 Defined PC84BM Traps in Organic Bulk Heterojunction Solar Cells, Adv. Funct. Mater. 
2 [26] S. Nam, D.S. Chung, J. Jang, S.H. Kim, C. Yang, S.-K. Kwon, C.E. Park, Effects of 3 Poor Solvent for Solution-Processing Passivation of Organic Field Effect Transistors, J. $4 \quad$ Electrochem. Soc. 157 (2010) H90. doi:10.1149/1.3251337.

5 [27] M. Campoy-Quiles, T. Ferenczi, T. Agostinelli, P.G. Etchegoin, Y. Kim, T.D. 6 Anthopoulos, P.N. Stavrinou, D.D.C. Bradley, J. Nelson, Morphology evolution via 7 self-organization and lateral and vertical diffusion in polymer:fullerene solar cell blends,

21 (2011) 3083-3092. doi:10.1002/adfm.201100514. Nat. Mater. 7 (2008) 158-164. doi:10.1038/nmat2102.

[28] J.A. Love, S.-H. Chou, Y. Huang, G.C. Bazan, T.-Q. Nguyen, Effects of solvent additive on "s-shaped" curves in solution-processed small molecule solar cells, Beilstein J. Org. Chem. 12 (2016) 2543-2555. doi:10.3762/bjoc.12.249.

[29] P.W.M. Blom, V.D. Mihailetchi, L.J.A. Koster, D.E. Markov, Device Physics of Polymer:Fullerene Bulk Heterojunction Solar Cells, Adv. Mater. 19 (2007) 1551-1566. doi:10.1002/adma.200601093.

[30] V.D. Mihailetchi, L.J.A. Koster, P.W.M. Blom, C. Melzer, B. de Boer, J.K.J. van Duren, R.A.J. Janssen, Compositional Dependence of the Performance of Poly(p-phenylene vinylene):Methanofullerene Bulk-Heterojunction Solar Cells, Adv. Funct. Mater. 15 (2005) 795-801. doi:10.1002/adfm.200400345.

[31] V.D. Mihailetchi, H.X. Xie, B. de Boer, L.J.A. Koster, P.W.M. Blom, Charge Transport and Photocurrent Generation in Poly(3-hexylthiophene): Methanofullerene BulkHeterojunction Solar Cells, Adv. Funct. Mater. 16 (2006) 699-708. doi:10.1002/adfm.200500420.

[32] S.R. Cowan, A. Roy, A.J. Heeger, Recombination in polymer-fullerene bulk heterojunction solar cells, Phys. Rev. B Condens. Matter. 82 (2010) 245207. doi:10.1103/PhysRevB.82.245207. 
1 [33] S.R. Cowan, R.A. Street, S. Cho, A.J. Heeger, Transient photoconductivity in polymer

2 bulk heterojunction solar cells: Competition between sweep-out and recombination,

3 Phys. Rev. B Condens. Matter. 83 (2011). doi:10.1103/PhysRevB.83.035205.

4 [34] A.K.K. Kyaw, D.H. Wang, V. Gupta, W.L. Leong, L. Ke, G.C. Bazan, A.J. Heeger, 5 Intensity Dependence of Current-Voltage Characteristics and Recombination in High$6 \quad$ Efficiency Solution-Processed Small-Molecule Solar Cells, ACS Nano. 7 (2013) 4569$7 \quad$ 4577. doi: $10.1021 / \mathrm{nn} 401267 \mathrm{~s}$.

8 [35] A.K.K. Kyaw, D.H. Wang, D. Wynands, J. Zhang, T.-Q. Nguyen, G.C. Bazan, A.J. 9 Heeger, Improved light harvesting and improved efficiency by insertion of an optical spacer $(\mathrm{ZnO})$ in solution-processed small-molecule solar cells, Nano Lett. 13 (2013) 3796-3801. doi:10.1021/n1401758g.

[36] A. Aghassi, C.D. Fay, A. Mozer, Investigation of S-shaped current-voltage characteristics in high-performance solution-processed small molecule bulk heterojunction solar cells, Org. Electron. $62 \quad$ (2018) 133-141. doi:10.1016/j.orgel.2018.07.025.

[37] A. Baumann, J. Lorrmann, D. Rauh, C. Deibel, V. Dyakonov, A new approach for probing the mobility and lifetime of photogenerated charge carriers in organic solar cells under real operating conditions, Adv. Mater. 24 (2012) 4381-4386. doi:10.1002/adma.201200874.

[38] T.M. Clarke, J. Peet, A. Nattestad, N. Drolet, G. Dennler, C. Lungenschmied, M. Leclerc, A.J. Mozer, Charge carrier mobility, bimolecular recombination and trapping in polycarbazole copolymer:fullerene (PCDTBT:PCBM) bulk heterojunction solar cells, Org. Electron. 13 (2012) 2639-2646. doi:10.1016/j.orgel.2012.07.037.

[39] M. Stephen, K. Genevičius, G. Juška, K. Arlauskas, R.C. Hiorns, Charge transport and its characterization using photo-CELIV in bulk heterojunction solar cells: Photo-CELIV 
1 to probe charge transport in solar cells, Polym. Int. 66 (2017) 13-25.

2 doi:10.1002/pi.5274.

3 [40] M. Kuik, L.J.A. Koster, G.A.H. Wetzelaer, P.W.M. Blom, Trap-assisted recombination

4 in disordered organic semiconductors, Phys. Rev. Lett. 107 (2011) 256805. 5 doi:10.1103/PhysRevLett.107.256805. 


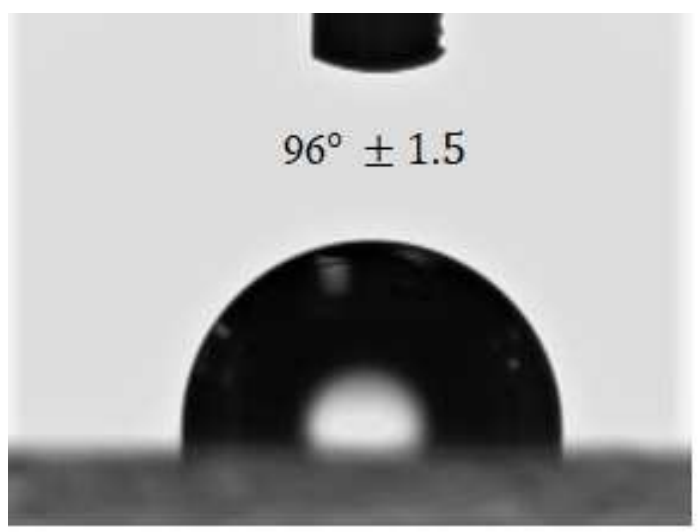

3 Before IPA treatment

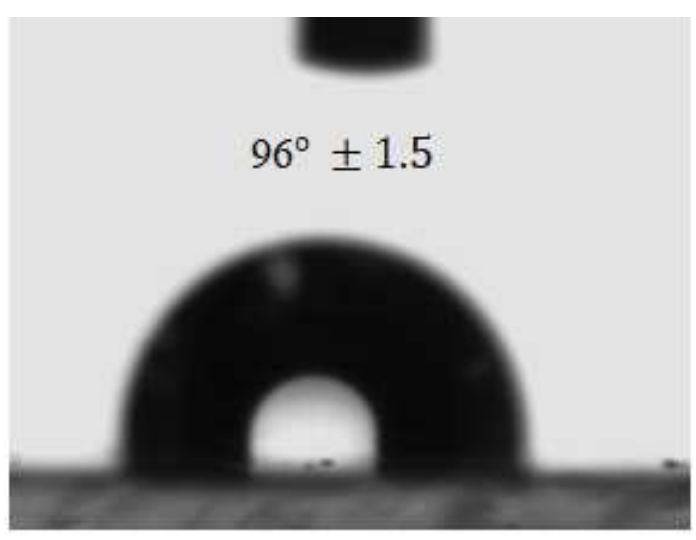

After IPA treatment

4 